\title{
A simple and fast method to determine water content in biodiesel by electrochemical impedance spectroscopy
}

\author{
José Rodrigues Delfino ${ }^{a}$, Thúlio C. Pereira ${ }^{\mathrm{a}}$, Helmara D. Costa Viegas ${ }^{\mathrm{a}}$, Edmar P. Marques ${ }^{\mathrm{a}}$, \\ Antônio A. Pupim Ferreira ${ }^{\mathrm{b}}$, Lei Zhang ${ }^{\mathrm{c}}$, Jiujun Zhang ${ }^{\mathrm{a}, \mathrm{c}}$, Aldaléa L. Brandes Marques ${ }^{\mathrm{a}, *}$ \\ a Federal University of Maranhão (UFMA) - Nucleus for Studies in Petroleum and Energy (NEPE): LPQA \& LAPQAP, Av. dos Portugueses, 1966, Bacanga, 65080-040 São \\ Luís, MA, Brazil \\ ${ }^{\text {b }}$ São Paulo State University Julio de Mesquita Filho - Institute of Chemistry, 14801-970 Araraquara, SP, Brazil \\ ${ }^{c}$ College of Sciences \& Institute for Sustainable Energy, Shanghai University, Shanghai 200444, China
}

\section{A R T I C L E I N F O}

\section{Keywords:}

Water content

Electrochemical impedance spectroscopy

Biodiesel

\begin{abstract}
A B S T R A C T
In this paper, a fast, simple and new alternative method for determination of water content (moisture) in biodiesel using electrochemical impedance spectroscopy (EIS) is developed. The method is based on the sensitive variation of the charge transfer resistance $\left(R_{c t}\right)$ of the biodiesel medium in the presence of different quantities of water. To obtain an accurate analytical measurement, a pre-treatment based on a simple dilution by acetonitrile is employed. The two identical Pt electrodes are used in the measurement cell filled with sample solution. The experiment conditions are also optimized for the measurements. The obtained analytical linear curve between the water content and EIS impedance is the basis for the water content analysis in biodesiel fuel. The EIS method is then successfully applied to both real and certified samples, and the results confirm that the method is reliable with high sensitivity, precision and accuracy. The comparison of EIS method with the official standard method is also made through the Student test $\mathrm{t}$, demonstrating that both methods are statistically consistent and similars. The validation of such an EIS method confirms that the method presented for the fist time in this paper can be succesessfully applied to determining the water content of biodiesel fuel.
\end{abstract}

\section{Introduction}

The sustainable and environmentally-beneficial biodiesel is a promising and alternative combustion fuel due to its energetic and physicochemical properties are similar to petroleum diesel. Furthermore, when used as the fuel, it is not necessary to adjust the diesel engines [1-3]. However, their marketing is subject to the fulfillment of standards and regulations governing the parameter control of biodiesel quality. Usually these standards / regulations are based on American (ASTM D6751), European (EN 14214) and Brazilian (ANP Resolution 45/2014) specifications, which establish the biodiesel quality standards. All these norms give to biodiesel fuel the specifications and adequate properties, including blend components, blend stock, neat automotive fuel and fuel purity [4-6].

Regarding the fuel purity, biodiesel contaminants are a major concern. The contaminants include metals [7-9], water [10], fatty acid methyl esters [11], sulphur [12], mono-,di- and triacylglycerides and free and total glycerol [13], methanol and ethanol [14], as well as iodine [15]. An important quality parameter for commercialization of biodiesel is the water content. As identified, even a small amount of water (moisture) can cause corrosion of fuel tank components, affecting the heat of combustion, supporting the growth of microorganisms, and favoring gelation at low temperatures $[10,16]$. In addition, a serious problem in biodiesel is the hydrolytic and oxidative degradation induced by the ester hydrolysis when water is present in the medium [17]. This biodiesel moisture may be induced by the processes of production, washing, storage and transportation due to the hygroscopic character of biodiesel $[10,17,18]$. Therefore, analysis of the water content in biodiesel is necessary for the quality control.

There are many established analytical methods for determining the quality parameters of biodiesel to ensure the good performance of the fuel and engines [7-15]. For water content analysis, the Karl Fisher method is the most widely adopted, but requires a sophisticated titrator, expensive reagents and qualified personnel to operate the equipment $[19,20]$. Other methods have also been proposed by the scientific community for determining the water content in different matrices [21]. However, using electrochemical method, particularly Electrochemical Impedance Spectroscopy (EIS), to determinate the

\footnotetext{
* Corresponding author

E-mail address: aldalea.ufma@hotmail.com (A.L. Brandes Marques).
} 
water content in biodiesel has not been fully established in literature.

EIS is a technique that can be used for various analytical purposes, such as corrosion [22-24], adsorption [25,26], functioning of batteries and fuel cells $[27,28]$, and measurement of the electrical conductivity for soils and sediments [29]. As recognized, EIS can distinguish individual contributions of different components to the electrochemical processes, based on the variation of time constants and other controlled variables [30].

Regarding the fuel component analysis, Kung et al. [31] developed an EIS impedimetric sensor for monitoring the ethanol and water contents in gasoline streaming using a pair of carbon electrodes. Their method could measure these parameters (water and ethanol contents) of the fuel in less than $1 \mathrm{~s}$ at $20-40{ }^{\circ} \mathrm{C}$ with good reproducibility and a relative standard deviation of $2 \%$. The water content was estimated by comparing the impedance data obtained with and without desiccation of the sample [30]. A further work on biodesiel fuel [32], they could measure the mixing ratio of biodiesel in diesel with less than $10 \mathrm{~s}$, using EIS with a pair of identically printed carbon paste electrodes. At low frequencies $(<1 \mathrm{~Hz})$, it was possible to estimate the mixing ratio of biodiesel $\left(\mathrm{r}^{2}>0.98\right)$ with good resolution, reproducibility and stability ( $\mathrm{CV}<3 \%, \mathrm{n}=8$ ), which is important for quality control and regulation of biofuel [32]. Perini et al. [33] developed a methodology employing EIS technique for in-situ analyzing and characterizing the water-in-oil emulsion. The results obtained by EIS measurements indicated that the analysis could be carried out on site without the need for sample preparation, allowing the characterization of crude oil emulsions and water-in-oil [33]. In our previous work, an EIS technique was explored as the tool to analyze the biodiesel content in petroleum diesel. The results indicated that the method was sufficiently suitable as an alternative way to the official one for determining biodiesel content in commercial diesel fuel [34].

As a continuing research to address the quality control through analyzing the water content in the biodiesel fuel, the EIS technique as an alternative method is further explored, and the results show that this method is simple and fast with good sensitivity and reproducibility.

\section{Experimental section}

\subsection{Apparatus}

The electrochemical measurements were performed in an electrochemical cell ( $500 \mu \mathrm{L}$ capacity) containing two identical Pt electrodes $\left(0.25 \mathrm{~cm}^{2}\right.$ geometric area) connected with a potentiostat equipped with AUTOLAB PGSTAR 302 and FRA 4.9 impedance module. The technique used to carry out the measurements was the electrochemical impedance spectroscopy (EIS) at open circuit potential (OCP). The electrical conductivity measurements were performed on a Digimed conductivity (MD 32 model).

\subsection{Reagents}

All reagents used were of analytical grade. The water used was distilled and deionized to a resistivity of $18.2 \mathrm{M} \Omega \mathrm{cm}^{-1}$, produced by a Barnstead Nanopure System - Thermo Scientific. The samples were prepared by diluting biodiesel in concentrated acetonitrile from Merck (Darmstadt, Germany). Both the electrochemical cell and electrodes were cleaned by $10 \%$ nitric acid solution, concentrated acetone, and then the deionized water.

\subsection{Sample preparation}

Methyl soybean biodiesel samples were produced in-house, using the biodiesel samples from the Interlaboratory Program (PIB-ANP) provided by the Research Laboratory of Analytical Chemistry of Petroleum and Biofuels (LAPQAP-Federal University of Maranhão).
Table 1

Optimized electrochemical parameters for the determination of water in biodiesel by electrochemical impedance spectroscopy.

\begin{tabular}{ll}
\hline Parameter & Specifications \\
\hline Frequency Range (Hz) & $10^{6}$ to $10^{-1}$ \\
OCP times & $20 \mathrm{~s}$ \\
Points per frequency decade & 10 \\
Amplitude & $50 \mathrm{mV}$ \\
\hline
\end{tabular}

\subsection{Analysis procedure}

The EIS measurements were performed in an electrochemical cell with sample solution which contained pure biodiesel and concentrated acetonitrile. When measuring the sample, successive additions of water aliquots into the cell were performed, and the impedimetric signal was measured. Table 1 shows the optimized experimental parameters used for the water content determination by the present method. The amplitude of the perturbation signal was $50 \mathrm{mV}$, since highly resistive systems require minimally small amplitudes $[34,42]$. The range of frequency adopted was $10^{6}$ to $10^{-1}$ in all experiments.

\section{Results and discussion}

\subsection{Preliminary study}

To optimize the experimental conditions for quantitative analysis of water content in biodiesel, three types of electrode were evaluated (glassy carbon, stainless steel and platinum (Pt)). Pt electrode showed the best results in terms of stability, resolution with lower dispersion of points, and response sensitivity.

Regarding the pre-treatment sample solutions, pure biodiesel could not give a satisfactory due to the resistive characteristics of this biofuel. Then microemulsion and biodiesel/acetonitrile were evaluated as the possible pre-treatment of the samples. Compared to microemulsion, the sample of biodesiel/acetonitrile presented very good results with suitable response from the electroanalytical point of view. Therefore, the biodesiel/acetonitrile solution was chosen as the pre-treatment sample for the subsequent studies.

In order to check the linearity of the system, the relationship between the values of impedance modulus $(|\mathrm{Z}| /|\mathrm{Z}|)$ and amplitude [35] at a frequency of $27.54 \mathrm{~Hz}$ from low to high amplitudes were obtained, which showed an excellent linearity. This linearity was considered essential for the reliability of EIS measurements. From the results, the amplitude of $50 \mathrm{mV}$ was chosen and considered suitable for the all subsequent experiments.

\subsection{Equivalent electrical circuit (EEC)}

Fig. 1 shows the Nyquist diagram and the corresponding Bode plot for biodiesel/acetonitrile sample. The proposed equivalent electrical circuit (Inset in Fig. 1(A)) is based on the characteristics of impedance spectra obtained in Fig. 1(A) and (B). The Nyquist diagram is characterized by a capacitive arc, followed by a second low frequency behavior that can be attributed to interfacial phenomena [36-38]. Bode plot in Fig. 1(B) shows a variation of the frequency with the log module impedance between $10^{6}$ and $10^{4} \mathrm{~Hz}$, indicating a capacitive behavior $\left(C_{d}\right)$. Between $10^{4}$ and $10^{1} \mathrm{~Hz}$, the modulus of impedance does not change with the magnitude of the impedance, indicating a resistive behavior [35-37].

The values of real and imaginary components are in the order of $\mathrm{K} \Omega \mathrm{cm}^{-2}$ and a good correlation between experimental and simulated data was obtained. In the proposed equivalent circuit (Inset in Fig. 1(A)), $R_{s}$ is the resistance of the solution, $Q$ is the capacitance of the electrical double layer, $R_{c t}$ is the charge transfer resistance, and CPE is 


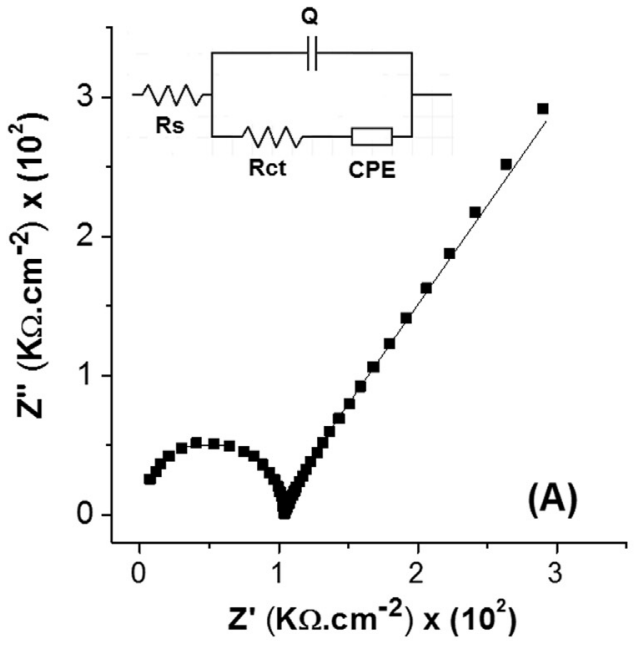

the constant phase element (pseudo capacitance) [37-41]. The capacitance of the double layer is dependent on the conductive or the insulating property of the interface, the charge transfer resistance is due to the electron transfer generated by the redox processes related to the electrolytic solution $[37,42]$.

The adjustments of the Nyquist diagrams were all done by trial until obtaining approximately the experimental curves by appropriate choice of parameter values. Table 2 shows the values obtained from the proposed electric circuit. All components are verified by the evaluation of the chi-square parameter at the magnitude order of $10^{-5}$ with a confidence level around $98 \%$.

These results clearly show that a comparison between the experimental and simulated data presented small errors, which show that the method is reliable and indicates a good analytical performance.

\subsection{Electrochemical behavior of Pt electrode in pure acetonitrile and biodiesel/acetonitrile}

The ideal biodiesel sample concentration in the biodiesel/acetonitrile mixture was evaluated through experiments with different sample concentrations covering the range between $0 \%$ and $40 \%$ biodiesel, in both the absence and presence of water. This study was important in order to establish the best conditions for the analysis. Impedance spectra for this experiment are showed in Fig. 2, which shows a growing increase of resistivity of the medium with increasing biodiesel concentration in the mixture. Akita et al. [43] also observed this behavior, which was attributed to the low conductivity of biodiesel $[43,44]$. We believe that the magnitude increase in the impedance semicircle $\left(\mathrm{R}_{\mathrm{ct}}\right)$ probably reflect the effect of the solution resistance on the kinetics of $\mathrm{Pt}$ surface charge transfer and reactant adsorption process. Further study is needed to identified the electrode processes on the Pt surface. In this work, the solution overall real impedance could be expressed as Eq. (1):

$\mathrm{Z}_{\mathrm{r}}=\mathrm{R}_{\mathrm{s}}+\mathrm{R}_{\mathrm{ct}} / 2$

where $R_{s}$ is the resistance of the solution, $R_{c t}$ is the resistance of Pt surface charge transfer, and $Z_{r}$ is the overall real impedance [45].

When the same experiment (Fig. 2) was carried out in the presence

Table 2

Parameters obtained from the adjustment performed based on the proposed equivalent circuit.

\begin{tabular}{llllll}
\hline & $\mathrm{R}_{\mathrm{sol}}(\mathrm{k} \Omega)$ & $\mathrm{Q}(\mathrm{pF})$ & $\mathrm{R}_{\mathrm{ct}}(\mathrm{k} \Omega)$ & $\mathrm{CPE}$ & Chi-Square \\
\hline Value & 2.60 & 5.97 & 120.4 & $0.34 \times 10^{-5}$ & $2.18 \times 10^{-5}$ \\
Error (\%) & 16.4 & 1.13 & 0.47 & 1.03 & - \\
\hline
\end{tabular}

Fig. 1. (A) - Nyquist diagram; (B) Bode plot, for a sample of $30 \% \mathrm{v} / \mathrm{v}$ of biodiesel in acetonitrile. The equivalent circuit for the system is presented in the inset figure; frequency range: $10^{6}-10^{-1} \mathrm{~Hz}$; amplitude: $50 \mathrm{mV}$; points per decade measurement: 10 ; OCP time: $20 \mathrm{~s}$.

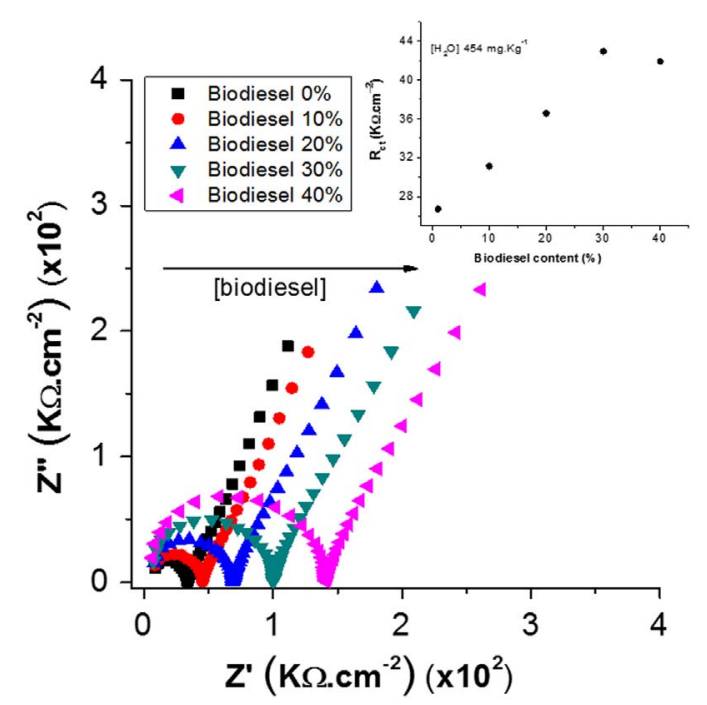

Fig. 2. Nyquist diagrams for the Pt electrodes for increasing biodiesel concentrations (the range between $0 \%$ and $40 \%$ biodiesel) in acetonitrile medium; Frequency range: $10^{6}-10^{-1} \mathrm{~Hz}$; amplitude: $50 \mathrm{mV}$; points per decade measurement: 10; OCP time: $20 \mathrm{~s}$. Inset figure shows $\mathrm{R}_{\mathrm{ct}}$ in acetonitrile medium as a function of biodesiel content in the presence of of $454 \mathrm{mg} \mathrm{kg}^{-1}$ of water.

of a constant concentration of water ( $454 \mathrm{mg} \mathrm{Kg}^{-1}$ ), a linear increase of $\mathrm{R}_{\mathrm{ct}}$ with increasing of the biodesiel content was observed (Inset in Fig. 2). However, after $30 \%$ of biodesiel content, the $\mathrm{R}_{\mathrm{ct}}$ value is slightly dropped, suggesting that $30 \%$ of biodesiel is the optimal value in terms of sensitivity for the method. Therefore, $30 \%$ was chosen for the other subsequent experiments.

From the point of view of the process that occurs, the electrical properties of water are large enough to cause a measurable change in $\mathrm{R}_{\mathrm{ct}}$, that is the principle explored in the present method. On the other hand, water has a high dielectric constant $\left(\varepsilon^{\prime}=80\right)$ compared to other materials, such as ethanol $\left(\varepsilon^{\prime}=24.30\right)$, diesel $\left(\varepsilon^{\prime}=2.0\right)$, and biodiesel $\left(\varepsilon^{\prime}=2.0-3.0\right)[46-49]$. The literature has also already shown that the presence of water droplets of nanometric size, dispersed in the oil phase, alter the conductivity [49].

About the electrolysis of water, it decomposes under high voltages, at around $3 \mathrm{~V}$. In the present study all experiments were carried out in open circuit potential (OCP), in order to obtain information about the processes occurring on the electrode surface, referent to its exposure to the medium, with minimal disturbance of the system, [48]. This certainly decreases or avoid electrolysis processes in the system studied. 


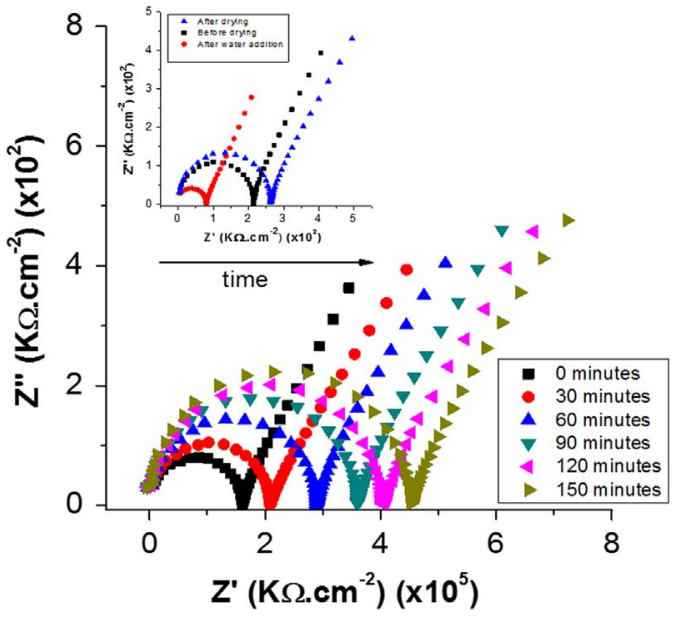

Fig. 3. Nyquist diagrams for Pt electrodes in $30 \% \mathrm{v} / \mathrm{v}$ biodiesel/acetonitrile mixture with increasing heat time. Operational conditions are the same as in Fig. 2. Inset figure shows Nyquist diagrams for acetonitrile solution containing 30\% v/v biodiesel before and after heat-treatment and with the addition of water.

\subsection{Influence of heat treatment on electrochemical response of the mixture}

To further confirm the effect of sample water content on EIS spectra, the experiments employing heat-treatment on biodiesel samples were carried out, as shown in Fig. 3. EIS measurements were performed before and after the heat-treatment of samples in an oven at $90{ }^{\circ} \mathrm{C}$. For a better understanding, the measurements were also made with and without addition of water. The temperature of $90{ }^{\circ} \mathrm{C}$ was chosen in order to avoid the loss of other compounds added to the commercial biodiesel, such as antioxidants, alcohols and other volatile compounds, which could somehow mask or influence the electrochemical response of the measurements of impedance.

The measurement was carried out after every $30 \mathrm{~min}$ of heating. An aliquot of the sample was withdrawn for EIS analysis, and the sample remainder continued being heating. This procedure was done successively, until the total time of $150 \mathrm{~min}$. EIS measurements were carried out with different drying times of biodiesel sample to demonstrate the dependence of solution resistance on the heating time (Fig. 3). It can be seen that $R_{c t}$ increases with increasing heat time. This observation can be attributed to the reduction of water content in the solution. This result also confirms the correlation of $\mathrm{R}_{\mathrm{ct}}$ with water content in biodiesel.

As can be seen from the Nyquist diagrams in Fig. 3 (inset figure), a value for the second intercept of about $2.1 \times 10^{2} \mathrm{~K} \Omega$ is obtained for the sample before any heating or water addition. A shift can be observed (increasing Z' from 210 to $280 \mathrm{k} \Omega$ ) when the sample is heated (dryed), indicating the increasing of resistivity due to the decreasing of water content in the sample. After addition of water to the mixture solution, a new variation of arc diameter is observed, indicating a decrease of resistivity due to the increase of the water content. This change in $\mathrm{R}_{\mathrm{ct}}$ can be attributed to the dehydration of biodiesel. Perini et al. [33] observed the similar results after dehydration by centrifugating oil samples during analysis of water content in oil sample emulsions.

\subsection{Analytical curve and application in real samples}

After studying the electrical properties and optimizing the main experimental conditions, measurements were carried out in $30 \% \mathrm{v} / \mathrm{v}$ biodiesel/acetonitrile mixtures in the presence of water. An analytical curve was constructed based on the EIS measurements with different amounts of water content, as shown in Fig. $4 \mathrm{~A}$, where $\mathrm{R}_{\mathrm{ct}}$ values are dependent on the water content in biodiesel. The analytical curve corresponds to the following water concentrations: 454.1, 908.3,
1362.4, $1816.5 \mathrm{mg} \mathrm{Kg}^{-1}$ (Fig. 4B).

Fig. 4 indicates that the addition of water in the solution decreases the $R_{\mathrm{ct}}$ value, and the diferences in $\mathrm{R}_{\mathrm{ct}}$ value are linearly dependent on water content (Equation: $y=2.66 \times 10^{2}-0.06 \mathrm{x}, \mathrm{r}^{2}$ : 0.995). In EIS studies conducted by Jafari et al. [38], this same behavior of $R_{c t}$ decreasing was also observed in the presence of water in gasoline.

We expected the resistance of biodiesel/acetonitrile medium was decreased because the polar compounds (especially water) contained in biodiesel are much more soluble in acetonitrile than in biodiesel, reducing the charge transfer resistance, as expected by the authors of a previous study [33], but this was not observed, experimentally in the present work. According to these authors [33] the increase in $\mathrm{R}_{\mathrm{ct}}$ was attributed to the stability of the emulsions and the formation of rigid films at the water-oil interfaces, and not directly to the quantity of water.

The electrical conductivity results that we have obtained indicated that the conductivity of the medium was actually increased proportionally with the addition of water. This behavior was evidenced much more in the EIS measurements, what is attributed to the higher sensitivity of the EIS technique for charge transfer processes. Moreover, due to the presence of ester bonds, biodiesel has a higher polarity than the petroleum [33], consequently, biodiesel has a much greater tendency to absorb moisture [50]. This fact indicates that the water content contributes much more to the decrease in the charge transfer resistance in the biodiesel, as verified in the studies carried out by EIS in the literature and in the present work.

In previous studies carried out to characterize acetonitrile adsorption on platinum surface, an increasing in the charge transfer resistance was observed with increasing water content in the solution, suggesting that both acetonitrile and water were adsorbed onto the electrode surface [51-53].

Some studies from the literature have already reported the use of acetonitrile as a solvent for water content determination [20,53-55]. Those studies were based on the fact that most hydrophobic matrices such as biodiesel, oils and lubricants are immiscible in acetonitrile. Therefore, acetonitrile is considered to be a simple and efficient medium for determining the water content. On the other hand, the method indicates a good selectivity, compared to other molecules, which is attributed to the this high affinity of acetonitrile by the water. Besides, the fact the water be a molecule that has only polar characteristics, while other possible interferents like alcohols are both polar and nonpolar $[48,54,56]$, indicates a higher selectivity of EIS measurements in acetonitrile medium for water compared to the other molecules.

Based on those early findings and the results presented in Fig. 4, it is possible to see a new and feasible method to measure the water content in biodiesel. The analytical curve shown in Fig. 4(B) is obtained by the standard addition method, and shows a good linear relationship between water content and $\mathrm{R}_{\mathrm{ct}}$ with a linear regression medium value for the correlation coefficient of 0.995 .

In a further study, the conductivity measurements were also conducted in order to verify and confirm the feasibility of the present method. In this study, conductivity measurements were performed without adding any water into biodiesel/acetonitrile mixture, which was used as the reference. After successive additions of water in the medium (454.1, 908.3, 1362.4, 1816.5 and $2270.7 \mathrm{mg} \mathrm{kg}^{-1} \mathrm{H}_{2} \mathrm{O}$ ), the corresponding conductivities were measured and the obtained results were consistent with those obtained by impedance in terms of both dependency and linearity (Equation: $y=0.24-4.23 \times 10^{-5} x, r^{2}$ : 0.999). In this case, an increase in conductivity was obtained with increasing water content. However, the value differences were less pronounced than EIS measurements, indicating that EIS technique is much more sensitive and more analytically appropriate.

The EIS method described above was applied to a sample which was certified through an official interlaboratory program of the Brazilian government (Interlaboratory Program for Biodiesel of National Agency 

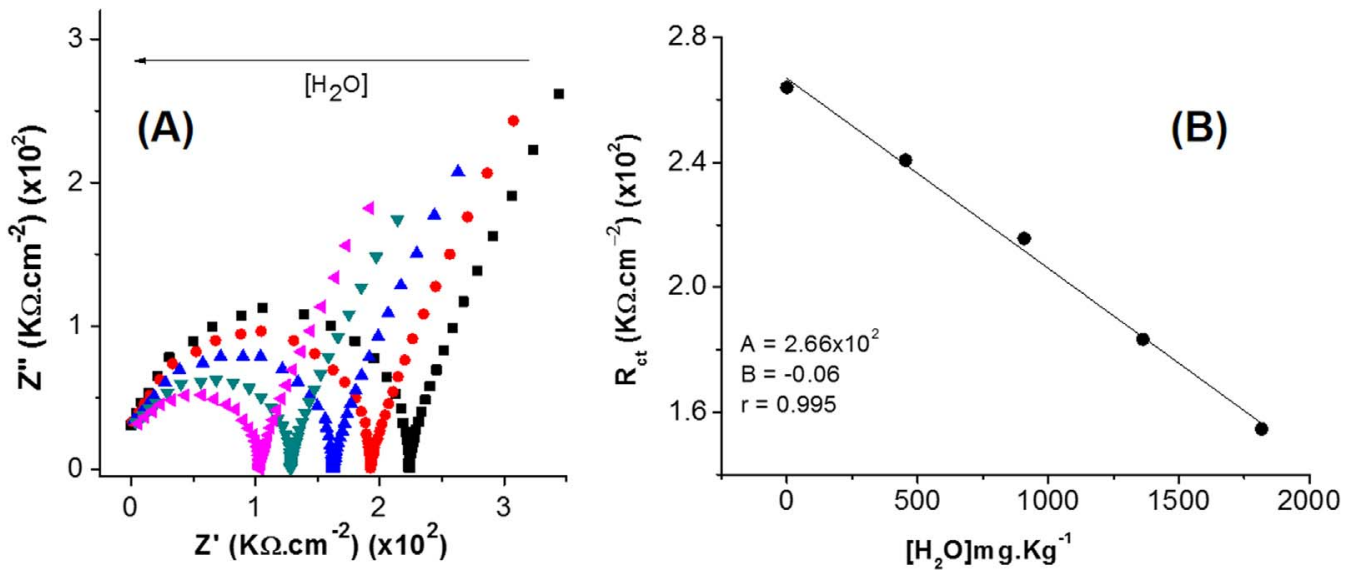

Fig. 4. Nyquist diagrams (A) and analytical curve (B) (showing the linear dependence between the $R_{c t}$ value and the water content in biodiesel), recorded in $30 \% \mathrm{v} / \mathrm{v}$ biodiesel/ acetonitrile solution, before (black) and after successive additions of water. Operational conditions are the same as in Fig. 2.
Table 3

Merit parameters obtained from the determination of water content in biodiesel in a real and certified sample by the present method.

\begin{tabular}{|c|c|}
\hline Parameter & Sample water content $\left(\mathrm{mg} \mathrm{Kg}^{-1}\right)$ \\
\hline$\mu\left(\mathrm{mg} \mathrm{Kg}{ }^{-1}, 95 \%\right)$ & $459.45 \pm 3.06$ \\
\hline SD & 3.06 \\
\hline RSD (\%) & 0.67 \\
\hline $\mathrm{LOD}\left(\mathrm{mg} \mathrm{Kg}^{-1}\right)$ & 0.2 \\
\hline LOQ $\left(\mathrm{mg} \mathrm{Kg}^{-1}\right)$ & 0.55 \\
\hline Sensibility $\left(\Omega / \mathrm{cm}^{2} \mathrm{Kg} \mathrm{mg}^{-1}\right)$ & 55.39 \\
\hline Accuracy (recovery) & $101.3 \%$ \\
\hline
\end{tabular}

of Petroleum, Natural Gas and Biofuels (PIB)/ANP), as courtesy of LAPQAP UFMA laboratory. The analysis was made in triplicate in order to validate the results from the analytical and statistical point of view (Table 3).

The accuracy was assessed through recovery tests. After adding known amounts of water, the samples could give a recovery of $101.3 \%$. The results indicated a good accuracy of the proposed method, which should be able to serve as a method for the analysis of water content in biodiesel using EIS technique.

The medium value of water content in the sample was calculated as the ratio between the linear coefficient and the slope of the curve. The results obtained in replicates $(n=3)$ showed an average water content of $459.5 \pm 3.1 \mathrm{mg} \mathrm{kg}^{-1}$. Considering the standard value from the certified sample $\left(450.0 \mathrm{mg} \mathrm{kg}^{-1}\right)$, this result indicated only a small error ranging between $1.4 \%$ and $2.8 \%$. According to official regulations $[4,6]$, this value should be reasonably accurate for this type of biofuel.

It can also be seen that the relative standard deviation (RSD) is $0.67 \%$ for the sample of biodiesel, indicating a good precision of the EIS procedure. The values found for the limit of detection (LOD) $\left(0.2 \mathrm{mg} \mathrm{kg}^{-1}\right)$ and the limit of quantification (LOQ) $\left(0.55 \mathrm{mg} \mathrm{kg}^{-1}\right)$ are also considered good and adequate for analysis of water content in biodiesel.

\subsection{Comparison of the present method with the official method and some work reported in literature}

The present method was compared with the Karl Fisher method (the official method (ANP Resolution 45/2014, based on EN ISO 12937)) using two biodiesel samples. Table 4 presents the values obtained for the biodiesel samples from soybean and bovine fat mixed oils.

The results shown in Table 4 are statistically concordants in terms of water content determination in the biodiesel samples. The value obtained for $t_{\text {cal }}$ for the two samples were less than the value for $t_{\text {tab }}$ considering a confidence level of 95\%, indicating that both methods are statistically equivalent. These results also indicate that there is not significative interferences in the method. In spite of in acetonitrile other
Table 4

Student test $\mathrm{t}$ for biodiesel samples (soybean and bovine fat mixed oils) by the proposed method (EIS) and the official standard method, Karl Fisher.

\begin{tabular}{|c|c|c|c|}
\hline Average value & $\mathrm{Pt} / \mathrm{EIS}$ & & Karl Fisher \\
\hline $\mathrm{X}_{\text {average } 1}\left(\mathrm{mg} \mathrm{Kg}^{-1}\right)$ & 460.6 & & 486.8 \\
\hline $\mathrm{X}_{\text {average } 2}\left(\mathrm{mg} \mathrm{Kg}^{-1}\right)$ & 512.7 & & 540.6 \\
\hline \multicolumn{4}{|c|}{ Teste-t de Student (Sample 01) } \\
\hline$t_{\mathrm{cal}}$ & & -4.03 & \\
\hline$t_{\text {tab }}$ & & 4.30 & \\
\hline Relationship $t_{\mathrm{cal}}$ and $\mathrm{t}_{\mathrm{tab}}$ & & $\mathrm{t}_{\mathrm{cal}}<\mathrm{t}_{\mathrm{tab}}$ & \\
\hline \multicolumn{4}{|c|}{ Teste-t de Student (Sample 02) } \\
\hline$t_{\mathrm{cal}}$ & & -3.74 & \\
\hline$t_{\text {tab }}$ & & 4.30 & \\
\hline Relationship $t_{\mathrm{cal}}$ and $\mathrm{t}_{\mathrm{tab}}$ & & $\mathrm{t}_{\mathrm{cal}}<\mathrm{t}_{\mathrm{tab}}$ & \\
\hline
\end{tabular}

species are extracted, such as alcohols, phenolic compounds, hydroperoxides and organic acids, [54], the affinity of acetonitrile by the water and its polar characteristics [56] can justify this observed selectivity.

Table 5 presents some studies reported in literature concerning the analysis of the water content in different matrices by electrochemical techniques (EQ) and infrared (IR). It can be seen that the EIS method can achieve good results when compared to other published methods. Therefore, the present EIS study is the most complete in terms of analytical evaluation including the analytical sensitivity, limit of detection and limit of quantification.

On the other hand, in terms of sample treatment, although three studies done in untreated samples, the solubilization of the sample in acetonitrile (present work) can be considered a very simple procedure which is only a dilution in an adequate solvent.

Regarding RSD, only one work presented a value less than $0.67 \%$. The other ones presented values much superior (1.5\% and $1.84 \%)$. These results confirm the good precision of the present work.

\section{Conclusion}

The present study shows that the variation of water content in biodiesel diluted in acetonitrile is proportional to the variation of electrode/solution impedance, based on which a new method of EIS measurements for the determination of the water content in biodiesel is developed.

After optimizing the experimental conditions, the analytical linear curve between the water content and EIS impedance is obtained. The EIS method is then successfully applied to both real and certified samples, and the results confirm that the method is reliable with high sensitivity, precision and accuracy.

The comparison of EIS method with the official standard method through the Student test $\mathrm{t}$ demonstrated that both methods are 
Table 5

Comparison of analytical methods for the determination of water described in literature.

\begin{tabular}{|c|c|c|c|c|c|}
\hline & Method 01* & Method $02[30]$ & Method $03[20]$ & Method 04 [10] & Method 05 [32] \\
\hline Electrode(s) & Pt & Glassy carbon & - & - & Pt \\
\hline Sample & Biodiesel & Gasoline & Edible oils & Biodiesel & Petroleum \\
\hline Technical & EIS & EIS & FTIR spectroscopy & FTIR spectroscopy & EIS \\
\hline Treatment of the sample (electrolyte) & Acetonitrile & Untreated & Acetonitrile & Untreated & Untreated \\
\hline RSD & $0.67 \%$ & $1.5 \%$ & $0.05 \%$ & $1.84 \%$ & - \\
\hline Sensibility $\left(\Omega / \mathrm{cm}^{2} \mathrm{Kg} \mathrm{mg}^{-1}\right)$ & 55.39 & - & - & - & - \\
\hline Detection limit $\left(\mathrm{mg} \mathrm{Kg}^{-1}\right)$ & 0.2 & - & - & $<0.05 \%$ & - \\
\hline Limit of quantification $\left(\mathrm{mg} \mathrm{Kg}^{-1}\right)$ & 0.55 & - & - & - & - \\
\hline
\end{tabular}

(*) EIS method in this paper; (-) Not provided.

statistically similar, what also indicated that there was not any interference on the obtained results.

The obtained results demonstrated that the method developed in this paper can be succesessfully applied to determining the water content of biodiesel fuel.

\section{Acknowledgements}

The authors are grateful to the funding agencies for the financial support and grants received: FINEP 2644/09 Contract No. 0110078404 (Research Project RECOL 05 / Subproject NANOPET), FAPEMA (UNIVERSAL-00799/14 and INFRA-03578/13), CNPq (PQ 2014, Proc / 2014 - 4) and ANP (Contract No. 1,029 / 2016-ANP-007,639). We also thank to the LAPQAP for providing biodiesel samples and to the Doctoral Program in Biodiversity and Biotechnology (BIONORTE/ UFMA).

\section{References}

[1] F. Kraxner, E.M. Nordstrom, P. Havlık, M. Gusti, A. Mosnier, S. Frank, H. Valin, S. Fritz, S. Fuss, G. Kindermann, I. McCallum, N. Khabarov, H. Bottcher, L. See, K. Aoki, E. Schmid, L. Máthé, M. Obersteiner, Global bioenergy scenarios - future forest development, land-use implications, and trade-offs, Biomass Bioenergy 57 (2013) 86-96.

[2] S. Jaichandar, K. Annamalai, The status of biodiesel as an alternative fuel for diesel engine - an overview, J. Sustain. Energy Environ. 2 (2011) 71-75.

[3] E.P.C. Lai, Biodiesel: environmental friendly alternative to petrodiesel, J. Pet. Environ. Biotechnol. 5 (2014) 1-2.

[4] American society of testing materials, ASTM D 6751.

[5] BSEN14538/2006. Fat and oil derivatives. Fatty acid methyl ester (FAMEs). Determination of $\mathrm{Ca}, \mathrm{K}, \mathrm{Mg}$, and $\mathrm{Na}$ content by optical emission spectral analysis with inductively coupled plasma (ICP-OES).

[6] BRAZIL. Agência Nacional de Petróleo Gás Natural e Biocombustíveis (ANP) Resolução $\mathrm{n}^{\circ}$ 45, de 25 de agosto de 2014. Published in the Brazilian Official Gazette on August 25, 2014.

[7] L. Pinto, S.G. Lemos, Multivariate optimization of the voltammetric determination of $\mathrm{Cd}, \mathrm{Cu}, \mathrm{Pb}$ and $\mathrm{Zn}$ at bismuth film. Application to analysis of biodiesel, Microchem. J. 110 (2013) 417-424.

[8] J.M.S. Almeida, R.M. Dornellas, S. Yotsumoto-Neto, M. Ghisi, J.G.C. Furtado, E.P. Marques, R.Q. Aucélio, A.L.B. Marques, A simple electroanalytical procedure for the determination of calcium. in biodiesel, Fuel 115 (2014) 658-665.

[9] E.S. Chaves, M.T.C. Loos-Vollebregt, A.J. Curtius, F. Vanhaecke, Determination of trace elements in biodiesel and vegetable oil by inductively coupled plasma optical emission spectrometry following alcohol dilution, Spectrochim. Acta Part B 66 (2011) 733-739.

[10] M.E.S. Mirghani, N.A. Kabbashi, M.Z. Alam, I., Y. Qudsieh, M.F.R. Alkatib, Rapid method for the determination of moisture content in biodiesel using FTIR spectroscopy, J. Am. Oil Chem. Soc. 88 (2011) 1897-1904.

[11] M.E. Borges, L. Díaz, J. Gavín, A. Brito, Estimation of the content of fatty acid methyl esters (FAME) in biodiesel samples from dynamic viscosity measurements, Fuel Process. Technol. 92 (2011) 597-599.

[12] H.D.C. Viégas, J.M.S. Almeida, C.A. Lacerda, J.B. Silva, A.L.B. Marques, E.P. Marques, A rapid and sensitive voltammetric determination of sulphur in biodiesel in samples no treated and treated with TMAH, Fuel 202 (2017) 464-469.

[13] C.P. Prados, D.R. Rezende, L.R. Batista, M.I.R. Alves, N.R. Antoniosi Filho, Simultaneous gas chromatographic analysis of total esters, mono-, di- and triacylglycerides and free and total glycerol in methyl or ethyl biodiesel, Fuel 96 (2012) 76-481.

[14] J.H.F. Boog, E.L.C. Silveira, L.B. Caland, M. Tubino, Determining the residual alcohol in biodiesel through its flash point, Fuel (2011) 905-907.

[15] M. Tubino, J.A. Aricetti, A green potentiometric method for the determination of the iodine number of biodiesel, Fuel 103 (2013) 1158-1163.
[16] I.M. Atadashi, M.K. Aroua, A.R. Abdul Aziz, N.M.N. Sulaiman, The effects of water on biodiesel production and refining technologies: a review, Renew. Sustain. Energy Rev. 16 (2012) 3456-3470.

[17] N. Kumar, Oxidative stability of biodiesel: causes, effects and prevention, Fuel 190 (2017) 328-350.

[18] A.S.M.A. Haseeb, H.H. Masjuki, L.J. Ann, M.A. Fazal, Corrosion characteristics of copper and leaded bronze in palm biodiesel, Fuel Process. Technol. 91 (2010) 329-334

[19] I.P. Lobo, S.L.C. Ferreira, R.S. Cruz, Biodiesel: parâmetros de qualidade e métodos analíticos, Quím. Nova 32 (2009) 1596-1608.

[20] X. Meng, J. Sedman, F.R. Van de Voort, Improving the determination of moisture in edible oils by FTIR spectroscopy using acetonitrile extraction, Food Chem. 135 (2012) 722-729.

[21] R.M. Balabin, E.I. Lomakina, R.Z. Safieva, Neural network (ANN) approach to biodiesel analysis: analysis of biodiesel density, kinematic viscosity, methanol and water contents using near infrared (NIR) spectroscopy, Fuel 90 (2011) 2007-2015.

[22] K. Al-Muhanna, K. Habib, Corrosion behavior of different alloys exposed to continuous flowing seawater by electrochemical impedance spectroscopy (EIS), Desalination 250 (2010) 404-407.

[23] L. Díaz-Ballote, J.F. López-Sansores, L. Maldonado-López, L.F. Garfias-Mesias, Corrosion behavior of aluminum exposed to a biodiesel, Electrochem. Commun. 11 (2009) 41-44.

[24] W. Wang, P.E. Jenkins, Z. Ren, Electrochemical corrosion of carbon steel exposed to biodiesel/simulated seawater mixture, Corros. Sci. 57 (2012) 215-219.

[25] O.R. Cámara, L.B. Avalle, F.Y. Oliva, Protein adsorption on titanium dioxide: effects on double layer and semiconductor space charge region studied by EIS, Electrochim. Acta 55 (2010) 4519-4528.

[26] L. Yang, M. Liu, X. Lei, Y. Zhang, Study on the adsorption behavior of $\gamma$-GPS on low carbon steel surfaces using RA-IR, EIS and AFM, Appl. Surf. Sci. 257 (2011) 9895-9903.

[27] D. Chun, D. Kim, Z.R. Williamson, T. Lee, C.W. Squibb, Investigation of fin based oxygen supply modules on the performance of air-breathing polymer electrolyte membrane fuel cells, Appl. Therm. Eng. 50 (2013) 293-301.

[28] H. Wang, Y. Shi, N. Cai, Characteristics of liquid stannum anode fuel cell operated in battery mode and $\mathrm{CO} / \mathrm{H}_{2} /$ carbon fuel mode, J. Power Sources 246 (2014) 204-212.

[29] X. Li, X. Wang, Q. Zhao, Y. Zhang, Q. Zhou, In situ representation of soil/sediment conductivity using electrochemical impedance spectroscopy Sensores, Sensors 16 (5) (2016) 625

[30] C. Ulrich, H. Petersson, H. Sundgren, F. Bjorefors, C. Krantz-Rulcker, Simultaneous estimation of soot and diesel contamination in engine oil using electrochemical impedance spectroscopy, Sens. Actuators B 127 (2007) 613-618.

[31] Y. Kung, T. Cheng, R. Chen, Impedimetric sensing of the ethanol and water contents in gasohol with a flow-through carbon electrode pair, Meas. Sci. Technol. 24 (2013) 105-107.

[32] Y. Kung, B. Hsieh, T. Cheng, C. Huang, R. Chen, Impedimetric sensing of the biodiesel contents in diesel fuels with a carbon paste electrode pair, Fuel 102 (2012) 724-728.

[33] N. Perini, A.R. Prado, C.M.S. Sad, E.V.R. Castro, M.B.J.G. Freitas, Electrochemical impedance spectroscopy for in situ petroleum analysis and water-in-oil emulsion characterization, Fuel 91 (2012) 224-228.

[34] T.C. Pereira, J.R. Delfino, A.A.P. Ferreira, F.J.S. Barros, E.P. Marques, J. Zhang A.L.B. Marques, Stainless steel electrodes to determine biodiesel content in petroleum diesel fuel by electrochemical impedance spectroscopy, Electroanalysis 29 (2017) 814-820.

[35] M.E. Orazem, B. Tribollet, Electrochemical Impedance Spectroscopy, 1st ed., John Wiley \& Sons Inc, New Jersey, 2008.

[36] S. Wolynec, Técnicas Eletroquímicas em Corrosão; Wolynec, S.: EDUSP, 2003.

[37] T. Pajkossy, R. Jurczakowski, Electrochemical impedance spectroscopy in interfacial studies, Curr. Opin. Electrochem. 1 (2017) 53-58.

[38] H. Jafari, M.H. Idris, A. Ourdjini, H. Rahimi, B. Ghobadian, EIS study of corrosion behavior of metallic materials in ethanol blended gasoline containing water as a contaminant, Fuel 90 (2011) 1181-1187.

[39] H. Pang, C. Wei, X. Li, G. Li, Y. Ma, S. Li, J. Chen, J. Zhang, Microwave-assisted synthesis of $\mathrm{NiS}_{2}$ nanostructures for supercapacitors and cocatalytic enhancing photocatalytic $\mathrm{H}_{2}$ production, Sci. Rep. 4 (2014) 3577.

[40] H. Pang, J. Deng, J. Du, S. Li, J. Li, Y. Ma, J. Zhang, J. Chen, Porous nanocubic $\mathrm{Mn}_{3} \mathrm{O}_{4}-\mathrm{Co}_{3} \mathrm{O}_{4}$ composites and their application as electrochemical supercapacitors, 
Dalton Trans. 41 (2012) 10175-10181.

[41] X. Tan, Z. Zhou, M.M.-C. Cheng, Electrowetting on dielectric experiments using graphene, Nanotechnology 23 (2012) 37550.

[42] M. Chirea, Electron transfer at gold nanostar assemblies: a study of shape stability and surface density influence, Catalysts 3 (2013) 288-309.

[43] A.H. Akita, C.S. Fugivara, I.V. Aoki, A.V. Benedetti, Using the electrochemical impedance spectroscopy to characterize carbon steel in biodiesel medium, ECS Trans. 43 (2012) 71-77.

[44] J.-C. M'Peko, D.L.S. Reis, J.E. Sousa, A.R.L. Caires, Evaluation of the dielectric properties of biodiesel fuels produced from different vegetable oil feedstocks through electrochemical impedance spectroscopy, Int. J. Hydrog. Energy 38 (2013) 9355-9359.

[45] C.M.A. Brett, A.M.O. Brett, Eletrochemistry Principies, Methods and applicatons, 1st edition, Oxford University Press, 1993.

[46] P.D. Jensen, H. Hartmann, T. Bohm, M. Temmerman, F. Rabier, M. Morsing, Moisture content determination in solid biofuels by dieletric and NIR reflection methods, Biomass Bioenergy 30 (2006) 935-943.

[47] J.E. De Souza, M.D. Scherer, J.A.S. Cáceres, A.R.L. Caires, C. M’Peko, A close die letric spectroscopic analysis of diesel/biodiesel blends and potential dieletric approaches for biodiesel content assessment, Fuel 105 (2013) 705-710.

[48] M. Egashira, T. Izumi, N. Yoshimoto, M. Morita, Determining water content in activated carbon for double-layer capacitor electrodes, J. Power Sources 326 (2016) 635-640.

[49] Y.P. Silva, V. Dalmoro, Y.P.M. Ruiz, L.B. Capeletti, C.R.B. Mendonça, J.H.Z. dos
Santos, C.M.S. Piatnicki, Biodiesel water in oil microemulsions: ferrocene as a hydrophobic probe for direct analysis by differential pulse voltammetry at a Pt ultramicroelectrode, Anal. Methods 6 (2014) 9212-9219 (6).

[50] P.B.L. Fregolente, L.V. Fregolente, M.R. Wolf Maciel, Water content in biodiesel, diesel, and biodiesel-diesel blends, J. Chem. Eng. Date 57 (6) (2012) 1817-1821.

[51] A.V. Rudnev, E.B. Molodkina, A.I. Danilov, Yu.M. Polukarov, A. Berna, J.M. Feliu, Adsorption behavior of acetonitrile on platinum and gold electrodes of various structures in solution of 0.5 $\mathrm{M} \mathrm{H}_{2} \mathrm{SO}_{4}$, Electrochim. Acta 54 (2009) 3692-3699.

[52] A.T. Hubbard, E.Y. Cao, D.A. Stern, Surface analysis of electrodes by ultra-high vacuum techniques: acetonitrile solvent chemisorption AT Pt(111), Electrochem. Acta 39 (1994) 1007-1014.

[53] F.R. Van de Voort, J. Sedman, V. Yaylayan, C. Saint Laurent, C. Mucciardi, Quantitative determination of moisture in lubricants by Fourier transform infrared spectroscopy, Appl. Spectrosc. 58 (2) (2004) 193-198.

[54] F.R. Van de Voort, J. Sedman, R. Cocciardi, S. Juneau, An automated FTIR method for the routine quantitative determination of moisture in lubricants: an alternative to Karl Fischer titration, Talanta 72 (1) (2007) 289-295.

[55] A. Al-Alawi, F.R. Van de Voort, J. Sedman, A new Fourier transform infrared method for the determination of moisture in edible oils, Appl. Spectrosc. 59 (10) (2005) 1295-1299.

[56] K.S. Sidhu, J.M. Goodfellow, J.Z. Turner, Effect of molecular shape and electrostatic interactions on the water layer around polar and apolar groups in solution, J. Chem. Phys. 110 (16) (1999) 7943-7950. 